\title{
Can Law Improve Prevention and Treatment of Cancer?
}

Roger Magnusson

University of Sydney

Lawrence O. Gostin

Georgetown University Law Center, gostin@law.georgetown.edu

David Studdert

University of Melbourne

This paper can be downloaded free of charge from:

https://scholarship.law.georgetown.edu/ois_papers/34 


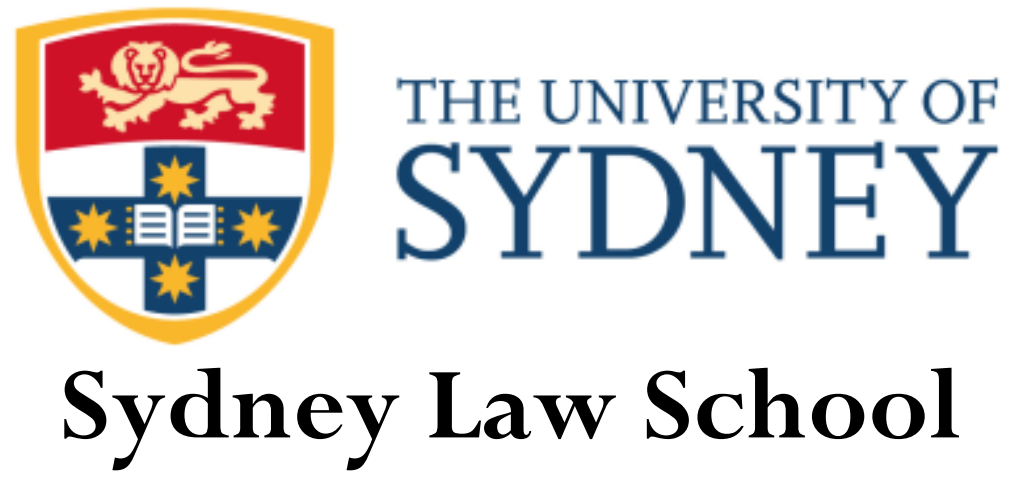

GEORGETOWN LAW

O’Neill Institute for National \& Global Health Law Scholarship

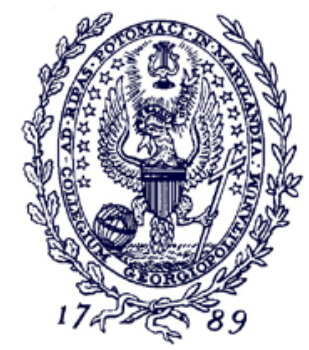

November 2011

University of Sydney School of Law Legal Studies Research Paper Series No. 11-88

Georgetown Public Law \& Legal Theory Research Paper No. 11-137

Georgetown Law and Economics Research Paper No. 11-29

\title{
Can Law Improve Prevention and Treatment of Cancer?
}

\section{Public Health (Forthcoming)}

\author{
Roger Magnusson, Faculty of Law, University of Sydney, School of Law \\ Larry Gostin, Professor of Law, Georgetown University Law Center \\ gostin@law.georgetown.edu \\ David M. Studdert, Faculty of Law \& Faculty of Medicine, \\ University of Melbourne, Dentistry and Health Sciences
}

This paper can be downloaded without charge from:

SSRN: http://ssrn.com/abstract $=1954470$ 


\title{
Can law improve prevention and treatment of cancer?
}

\author{
Symposium Introduction
}

On 19 September 2011, the United Nations High Level Summit on Non-Communicable Diseases (NCDs) adopted an historic declaration. The declaration calls for a multi-pronged campaign by governments, industry, and civil society to develop plans by 2013 to curb the risk factors for the four leading groups of NCDs - cardiovascular diseases, cancers, chronic respiratory diseases, and diabetes. ${ }^{1}$

In 2008, NCDs accounted for 36 million deaths (63\% of the global total), $80 \%$ of which occurred in low- and middle-income countries. ${ }^{2}$ The World Health Organisation (WHO) points out that with the exception of sub-Saharan Africa, NCD mortality "exceeds that of communicable, maternal, perinatal and nutritional conditions combined". 2,p9

Belatedly, NCDs have been recognized as a major obstacle to development. They entrench poverty and absorb scarce resources through treatment costs and lost productivity due to illness and premature death. ${ }^{3}$ The economic problem is compounded in low-income settings by the fact that household expenditure on NCD-inducing products, such as tobacco and alcoholic beverages, diverts household income away from much-needed goods such as food and education. ${ }^{4}$ NCDs represent not only a significant threat to global economic growth, ${ }^{5}$ but also signal the need to revise the working model for global development priorities, hitherto encapsulated in the Millennium Development Goals. ${ }^{6}$

The leading NCDs share preventable behavioural risk factors-chiefly, tobacco use, harmful use of alcohol, lack of physical activity, excess energy intake, and an unhealthy diet, which contribute, in turn, to elevated blood pressure, raised blood glucose, high cholesterol, and overweight and obesity. The leading NCDs share another similarity: progress is unlikely to come from self-regarding decisions taken by individuals alone, but will depend on comprehensive, national programs encompassing screening and early detection, policies for prevention, and the effective provision of health care services, including palliative care. ${ }^{2}$

The UN NCD Declaration urges the adoption of national polices ranging from price and tax increases to curb smoking to restrictions on the extensive marketing to children of foods and beverages that are high in saturated fats, trans-fatty acids, sugars, or salt. The Declaration similarly proposes measures to reduce the harmful consumption of alcohol, promote overall healthy diets, and increase physical activity.

The two-day NCD meeting at the General Assembly in New York was only the second highlevel summit in United Nation's history. The first summit, on AIDS, changed the world. Could the NCD Summit come even close to achieving the same impact? This seems unlikely. Although the Declaration may become an historic turning point in global health, and may 
eventually spark some re-calibration of effort and resources from infectious to chronic noncommunicable diseases, civil society expressed deep concerns with the Declaration's wording. Most controversial was the lack of urgency, specific targets and benchmarks, as well as the failure to include strategies to overcome barriers to access to essential medicines, particularly those posed by WTO and bilateral intellectual property agreements. The political declaration refers to the need for affordable, safe and effective medicines, and calls attention to flexibilities under the WTO trade-related aspects of intellectual property rights (TRIPS) agreement. ${ }^{7}$ However, it also studiously avoids any direct reference to NCDs as an "epidemic", signalling the expectation that low- and middle-income countries would be required to negotiate access to medications for NCDs on ordinary commercial terms, rather than opening the way for manufacture and supply of medications without the permission of the patent holder, on grounds of public health emergency. ${ }^{8}$

\section{A Focus on Cancer Prevention and Treatment}

Taking cancer as its focus, this symposium explores the possibilities for using law and regulation - both internationally and at the national level - as the policy instrument for preventing and improving the treatment of NCDs. There is an urgent need for more legal scholarship, and action, on cancer and other leading NCDs, together with greater dialogue between lawyers, public health practitioners and policy-makers about priorities for law reform, and feasible legal strategies for reducing the prevalence of leading risk factors. ${ }^{9}$

Global cancer incidence is high and rising. In 2008 there were nearly 13 million new cancer cases. By 2030, it is projected that there will be over 21 million new cases annually, with two thirds of these occurring in low- and middle-income countries. ${ }^{2}$ Hitherto, tobacco control has been the dominant focus of public health scholars interested in cancer prevention; only recently has attention broadened to acknowledge the importance of other risk factors, including obesity ${ }^{10}$ and the harmful use of alcohol. An integrated account of law's contribution to cancer prevention and treatment needs to take account of the wide range of modifiable determinants that have a legal dimension. These include measures such as HPV and HBV vaccination, sunbed regulation, and controls on exposure to environmental risk factors, such as asbestos and radiation. Population cancer screening programs including mammographic, cervical and colorectal screening - as well as cancer surveillance, reporting procedures and registries, are all important components of a comprehensive approach, and inevitably have a legal underpinning.

\section{The World Cancer Declaration and UICC's leadership}

This symposium is one of the outcomes of an international conference convened jointly by the Union for International Cancer Control (UICC) and the Sydney Law School on 10-11 June 
2010. UICC also hosted a session on legal approaches to cancer prevention and treatment at the World Cancer Congress held in Shenzhen, China, in August 2010. Both conferences were part of a process, which this symposium continues, of exploring how law could serve as a resource for governments and other stakeholders to achieve the targets and implement the priority actions set out in the World Cancer Declaration, developed by the UICC and endorsed by the World Cancer Congress in 2008. ${ }^{11}$ More generally, as NCDs become the leading cause of disease burden in high-, middle- and, increasingly, low-income countries, we want to signal the importance of scholarship in this area and to nudge the vocabulary of public health law in a new direction: so that it becomes meaningful to discuss legal and regulatory responses to cancer, heart disease and diabetes in a more comprehensive and coherent way.

One reason why there is a critical need for public health lawyers to engage with the challenge of cancer and NCDs is because successful implementation of many of the priority interventions for these diseases depends on legal and regulatory actions by governments. $^{2,9,12}$ Table 1 sets out the population-wide interventions for cancer and NCD prevention, as identified in the World Health Organisation's Global status report on $N C D s,{ }^{2, p p 47-60}$ that are most likely to require legal and regulatory measures. It also identifies those strategies that WHO has identified as most cost-effective ("best buys"), and locates each strategy within the WHO Framework Convention on Tobacco Control (2005) (FCTC), ${ }^{13}$ the WHO Global Strategy to Reduce the Harmful Use of Alcohol (2010), ${ }^{14}$ and the WHO Global Strategy on Diet, Physical Activity and Health (2004). ${ }^{15}$

The capacity of national and sub-national governments to implement these priority interventions through legislative and administrative actions will be affected by the constitutional structure of each country, including fundamental constitutional constraints on legislative power, and the division of legislative powers between tiers of government. Even in countries with a tradition of activism in tobacco control, some priorities remain breathtakingly ambitious. For example, despite the global impact of alcohol misuse, ${ }^{16}$ achieving restrictions on the sponsorship of sporting and cultural events by alcohol companies will require sustained efforts by public health and community groups - possibly for many years. As was the case with tobacco control, a coherent, comprehensive response to risk factors for cancer and NCDs, which includes a basket of legal and regulatory interventions, is likely to develop incrementally. Advocacy by public health practitioners will be critical to this process.

In this editorial, we set out some of the most significant obstacles that stand in the way of a more effective use of law for the prevention and control of NCDs, particularly cancer, and briefly identify some of the strategies that law can deploy.

\section{Unhealthy choices and unhealthy environments}


Of the many challenges that regulatory responses to risk factors for cancer and NCDs raise, two stand out. The first is the importance of unseating the popular view that, since risk factors like smoking, drinking to excess, eating a poor diet and living a sedentary lifestyle involve personal lifestyle choices, prevention is largely a matter of personal responsibility. The role of government, on this view, is limited to providing information and promoting a healthier lifestyle through mass media campaigns.

In well-quoted comments made in 2006, former UK Prime Minister Tony Blair said:

Our public health problems are not, strictly speaking, public health questions at all. They are questions of individual lifestyle - obesity, smoking, alcohol abuse, diabetes, sexually transmitted disease. These are not epidemics in the epidemiological sense. They are the result of millions of individual decisions, at millions of points in time. ${ }^{17}$

Framing cancer prevention purely in terms of "millions of individual decisions" fails to recognize that individuals, and their lifestyle preferences, do not exist in a vacuum. Choices are patterned and moulded by the physical environment, economic circumstances, and social relationships. ${ }^{18}$ Ignoring this makes for a disarmingly simple political philosophy that appeals to the way in which consumers value choice and control over their own lives. What escapes scrutiny, however, is the way in which corporate choices influence risks and behaviours across entire populations.

Freudenberg and Galea point out that:

No consumer ever entered a restaurant demanding a portion of trans fats. Rather, food companies constrain consumer options through decisions made primarily to increase profits. By exposing corporations as the real "nannies" who persuade children to eat to obesity...or patients to solve their social problems with a new drug, health professionals can reframe the discussion about who can be trusted to look after the public's health. ${ }^{19}$

While personal responsibility and self-control are powerful change strategies for individuals who wish to minimise health risks for cancer and NCDs, there is little evidence that delegating responsibility to the individual will be an effective prevention strategy at the population level. ${ }^{20-21}$

Road safety presents a useful analogy. Until relatively recently, fatigue, speed and driver error were widely seen as the major culprits in motor vehicle accidents and the human carnage crashes cause. These human factors have long been, and remain, important causes. But the impressive declines in road fatalities seen in many developed countries through the latter part of the twentieth century were due less to changes in driver behaviour than to radical redesign of vehicles and motorways to minimise the risks and consequences of accidents. ${ }^{22}$ 
As Table 1 illustrates, regulatory interventions that focus on improving the physical, economic and policy environment that lies outside of the individual have the advantage that they can support and empower both individuals and populations to live healthier lives. ${ }^{23}$ By focusing on the environment, rather than by directly targeting individuals and their behaviours, governments can avoid coercion and discrimination, and minimize direct interferences with personal autonomy.

On the other hand, placing the emphasis on healthier environments creates new challenges. The behavioural health risks in our lives are linked with commercial products and business interests in many complex ways. ${ }^{24}$ For example, motor cars, television and computer games play a large role in keeping us physically inactive. Socially constructed ideals around body image encourage the use of tanning solariums ${ }^{25}$ and undermine attempts to quit smoking for fear of weight gain. ${ }^{26}$ The advertising of energy-dense snacks and sugar-sweetened beverages contributes to weight gain, ${ }^{27-28}$ but so too might production and export subsidies for meat, sugar and oils, which are poorly aligned with nutritional guidelines but influence what goes into commodity foods. ${ }^{29-32}$ The question of whether alcohol labelling, food advertising, or some other aspect of business practice, deserves the attention of regulators depends on its contribution to the overall burden of disease. Yet this is not a straightforward issue for diseases and conditions that, like cancer, obesity or diabetes, have multiple environmental determinants. Just as importantly, regulation becomes a highly political issue for governments: which business-related determinants of disease should be selected out for regulatory control?

\section{Terms of engagement: tobacco, alcohol and food}

It is precisely because the priority interventions in Table 1 target the external environment, rather than individuals themselves, that they create the potential for conflict with the tobacco, alcohol, food, and retail industries. Again, the contemporary history of automobile safety is illuminating. Moves by Ralph Nader and other activists in the 1960s and 1970s to turn the spotlight from drivers to environmental determinants ${ }^{33}$ created instant conflict with the automobile industry. While confrontational approaches can yield breakthroughs in certain circumstances, it is almost certainly too blunt a strategy to fit all of the influences and actors in the NCD sphere. The second challenge for law reformers, therefore, is to determine the terms of engagement with these industries, including the prospects for partnerships and the merits of co-regulation.

There are significant differences between the tobacco, alcohol and food industries, despite the fact that all three benefit economically from the patterns of overconsumption that contribute to cancer and NCDs. The tobacco industry has a history of attempting to subvert public health efforts ${ }^{34}$ and to engineer tobacco products for taste and addictiveness. ${ }^{35}$ Guidelines made under the Framework Convention highlight the "fundamental and 
irreconcilable conflict between the tobacco industry's interests and public health policy interests"; they also point to the benefits of limiting interactions with the tobacco industry in order to protect the formulation and implementation of public health policies from industry influence to the "greatest extent possible". ${ }^{36}$ There is near consensus among public health experts that substantial regulation of the tobacco industry is a good thing, and that such regulation should focus both on limiting uptake of smoking, especially among children and youth, and helping existing smokers to quit. Over time, this strategy should continue the gradual contraction of the tobacco economy. Where these efforts flag, or are stymied, direct confrontation with the industry may well be appropriate.

With respect to alcohol, there is evidence that modest intake may reduce the risk of cardiovascular disease, ${ }^{37}$ although alcohol is also a neglected carcinogen, and cancer risk rises with level of consumption. ${ }^{16,38-39}$ As with tobacco, governments have an interest in supply-side regulation, because the sale of untaxed and informally-produced alcohol at lower prices both reduces government revenues and undermines public health goals. Reducing the burden of cancer requires substantial reductions in levels of alcohol consumption at the population level. However, selling moderation - and the forms of regulation most likely to result in more moderate levels of drinking - is extremely difficult. The alcohol industry is highly concentrated, innovative and global in scope. ${ }^{40}$ Although internal alcohol industry documents are generally unavailable, available sources illustrate a range of strategies to counter the threat of regulation. These include contesting the relationship between advertising and levels of consumption; support for voluntary, industrycontrolled educational initiatives; and focusing on individual rather than corporate responsibility. ${ }^{41-42}$

Although food is necessary for life, the WHO points out that reducing the burden of NCDs, including cancer, will require an overall reduction in calories, as well as reduced levels of consumption of salt, sugar and saturated fats at the population level. ${ }^{2,15}$ Factors that have contributed to weight gain and dietary imbalance include the reduced cost of food over time, particularly energy-dense carbohydrates; real income growth (leading to greater consumption of meat products and thus saturated fat); and the global marketing of preprepared meals and snack foods. Competition within the food sector leads to larger portion sizes and marketing that appeals to inbuilt preferences for sweet, fatty, salty, energy-dense foods. ${ }^{43-46}$

Yach and colleagues have argued that the solutions to obesity and diet-related disease partly depend on the "innovation and efficiency of the food industry". 47 They point to the need for public-private partnerships with government, researchers and community groups, combined with greater understanding of the constraints posed by food science, consumer behaviour, commodity prices and supply chains. ${ }^{48}$

On the one hand, the trust and goodwill required to make partnerships and voluntary regulation work may be difficult to achieve if the food industry - like the tobacco industry - 
is framed as a "vector of disease", and diet-related diseases as an "industrial epidemic" arising from the commercialization of unhealthy food. ${ }^{49}$ On the other hand, recent evidence suggests that without the spectre of regulation, the food industry has little commitment to its own voluntary pledges, ${ }^{50}$ and little interest in assisting consumers to make healthier food choices through, for example, evidence-based, front-of-pack traffic light labeling. ${ }^{51-52}$

\section{Symposium on legal approaches to cancer prevention and treatment}

There is no single blueprint for the legal interventions that could most effectively reduce cancer risks across the population. Although we believe that legal strategies have a role to play in reducing tobacco, alcohol and diet-related risks, there will be much to learn from sharing experiences between jurisdictions in the years ahead, and much to debate in the meantime.

Legislation is not a new phenomenon for cancer prevention. In the United States, for example, President Nixon's "war on cancer" led to the National Cancer Act of 1971 (P.L. 92218), which strengthened the role of the National Cancer Institute. More recently, in Australia, the Cancer Australia Act 2006 was introduced to provide national leadership in cancer control. As these examples illustrate, public health law is not only a tool for regulating business and the physical and economic environment; it is also a tool for reshaping the capacity of government, including local governments, to implement effective policies.

Table 2 sets out some of the principal ways in which law can help to reduce behavioural risk factors for cancer and other NCDs. It draws on Lawrence Gostin's model of law as a tool for public health. ${ }^{53}$ At the national level, familiar forms of regulation include economic interventions (such as taxes on tobacco and alcoholic beverages, or conditional grants from the federal government to state or local governments), as well as interventions in the informational environment (surveillance and reporting of risk factors, improved labelling and health warnings, and advertising controls). Global health governance, including international laws, global strategies and guidelines, also play a vital role in cancer control. As Table 1 illustrates, a consensus is emerging about the most promising legal measures for helping to reduce risks for cancer and other NCDs at the population level. ${ }^{2,12,54-55}$ These law reform priorities draw directly from the standards set out in the FCTC and from global strategies.

Global governance, as well as national-level regulation both feature in the contributions to this symposium. Robert Beaglehole, Ruth Bonita and Roger Magnusson set out the global context for this symposium by reviewing the global burden of cancer and the priority interventions for the leading risk factors. Around one third of cancer cases ( $>2.6$ million per year) are preventable with existing knowledge and interventions. As the authors illustrate, 
in addition to tobacco and alcohol control, a comprehensive response to cancer requires interventions to reduce obesity and promote physical activity, wider and more effective delivery of vaccinations for infectious causes of cancer, and renewed attention to environmental regulation, including radiation exposure, chemical safety, and sunbed regulation.

The growing focus on NCDs within the World Health Organisation, UN agencies and the World Bank has not been matched by sufficient consideration of the role of international economic law. Tania Voon and Andrew Mitchell examine the implications of World Trade Organisation (WTO) law for domestic regulatory efforts targeting common risk factors for NCDs: tobacco use, harmful use of alcohol, and poor diet. Although WTO law is often raised by tobacco companies and tobacco control advocates alike as a barrier to sensible health regulation, the authors argue that WTO agreements provide significant flexibilities for WTO member countries that wish to implement measures to protect public health, and can even be used as a tool to promote health policy. Voon and Mitchell conclude that international trade regulation should not be seen as an insurmountable obstacle to progressive regulation against cancer and other NCDs, or their risk factors.

The development, manufacture, trade and distribution of medicines all take place within a web of international legal obligations that states have accepted under a range of multilateral and bilateral agreements. Jonathan Liberman examines two areas of international law that are relevant to cancer treatment: the international drug control system, which regulates opioid analgesics, and the WTO's Trade-related aspects of intellectual property rights (TRIPS) agreement. ${ }^{7}$ Liberman outlines recent developments in relation to both, including the activities of the Vienna-based agencies that collectively oversee the implementation of the Single Convention on Narcotic Drugs, and the negotiations leading up to the recent United Nations General Assembly Political Declaration on Noncommunicable Diseases. ${ }^{1}$ While underlining the importance of law, Liberman points out that battles over law should not distract from the importance of other efforts to enhance access to medicines, as part of the process of strengthening national health systems.

Tobacco use remains the single most preventable cause of death globally. The Framework Convention on Tobacco Control (FCTC), ${ }^{13}$ which now has more than 170 parties and continues to influence national laws and policies, is the most powerful international legal tool currently in existence to reduce the global burden of NCDs. Katherine DeLand and Gemma Lien discuss how tobacco control gained traction as a topic for global governance, and review key successes and challenges in the six years since the FCTC came into force, including those relating to protocols negotiated under the FCTC. As the focus of global prevention efforts moves beyond tobacco, and as proposals are advanced for new international agreements on alcohol, obesity, and global health, ${ }^{56}$ DeLand and Lien consider whether the FCTC is a regulatory model that could be successfully deployed elsewhere. 
Having considered some of the leading legal and regulatory issues that arise at the global level, the papers in the symposium then turn to domestic laws and policies. In a longer paper, Roger Magnusson considers the case for using law to respond to cancer risks, and offers a framework for understanding how law could contribute to cancer prevention. He illustrates the application of this framework by taking Australia as a case study, evaluating priority areas for law reform at federal and state level, and placing these in the context of existing laws and policies. The framework outlined, as well as the law reform priorities and regulatory issues discussed, will be relevant to other countries with a substantial cancer burden.

While law can be a positive force for improving the treatment and prevention of cancer, it can also act as a barrier, as lan Olver argues. Olver identifies four areas where he believes Australian law and regulatory processes act as barriers to more effective cancer treatment. Privacy laws and concerns currently limit the electronic collection, linkage and sharing of patient data in ways that undermine effective patient treatment. Drug regulation processes also need updating, to ensure that regulatory approvals granted for targeted cancer treatments extend to the tests for identification of the target, as well as the drug itself. Olver argues that gene patenting laws have allowed patents for discoveries that add little in the way of innovation to clinical science and medicine, and that this threatens the widespread availability of emerging genetic tests and treatments for cancer. Finally, Olver explains how the burden of cancer and NCDs will require changes in the design of the health workforce, while maintaining safety and quality standards.

Turning to alcohol, Sondra Davoren points out that the policy and prevention literature focuses predominantly on the impact of alcohol policies over the short term. However, evidence is growing about the effect of interventions on long-term, alcohol-related chronic disease, including cancers. Davoren argues that experience with tobacco control supports interventions to increase the price of alcohol and to restrict its availability, in order to reduce consumption and to achieve longer-term health gains. Political inertia and the negative impact of the alcohol industry on the development of alcohol policy, she argues, are hampering legal interventions that could potentially save many lives. As the burden of alcohol-related cancers becomes more apparent, initiatives to introduce effective alcohol policies should be introduced sooner rather than later.

The environments where people live, learn, work, and play on a daily basis have a profound influence on health, by either promoting or discouraging behaviour associated with cancer and other chronic diseases. Advising individuals to increase their physical activity, avoid tobacco, and eat a diet rich in fruits and vegetables might motivate some people to make healthier choices, but their ability to do so hinges on access to an environment where healthy choices are readily available - where people can walk safely through neighborhood streets, breathe smoke-free air in their homes, and buy fresh produce at local stores. Marice Ashe, Samantha Graff and Carrie Spector point out that in the United States, local 
governments have tremendous latitude to regulate the physical environments that residents experience every day, through policies addressing physical activity, access to healthy foods, and the prevalence of tobacco products. Their paper looks at innovative ways to improve public health through laws and policies targeted specifically to local places, including schools, workplaces, recreational areas, food stores, and restaurants.

Legislative approaches to obesity prevention and healthier eating remain a highly contested area, even among public health advocates. Sarah Mackay outlines the roles that law could play, pointing out how the tendency to assess regulatory interventions through the frame of "personal responsibility" remains a barrier to political acceptance of legislative approaches. Mackay focuses in particular on the disclosure of nutritional information about food and beverage products, with the goal of better informing consumer choices and facilitating the exercise of personal responsibilities by individuals. She argues that political acceptance of law reforms in this area appears to be growing in Australia, and could provide a starting point for incremental progress in responding to diet-related risk factors for cancer and NCDs.

Finally, Cameron Stewart's paper deals with the reality of dying from cancer, and the law's management of the dying process. As cancer and other NCDs continue to be major causes of death, questions arise as to how law should regulate limitations upon treatment, and pain control for dying patients. Given the increasingly large proportion of people who will die in institutional care, the law's regulation of death management has become a "whole of population" issue that will affect the lives of many people. Stewart believes that law has a vital role in delivering the best possible end-of-life care, and sets out five desiderata that law should address. He also argues that poorly drafted laws can cause harm to patients, a process he refers to as nomoigenesis. Although Stewart illustrates his thesis about the disiderata and nomoigenesis by referring to Australian legislation, his arguments have broader application across a range of common law jurisdictions.

Encouraging governments to regulate for the sake of the health of populations is not an activity reserved for public health lawyers. Advocacy by public health professionals with a stake in improving the prevention and treatment of NCDs is crucial, but requires a measure of legal literacy and an understanding of the legal issues that cancer raises at global and national levels. This symposium issue of the journal was edited by Lawrence Gostin, Jonathan Liberman, Roger Magnusson, and David Studdert. We hope that this collection of papers will help to fulfil this role, and thank each of the authors for their contributions.

\section{References}

[1] United Nations General Assembly. Political declaration of the High-level Meeting of the General Assembly on the Prevention and Control of Non-communicable Diseases. A/66/L.1 (16 September 2011): http://www.un.org/en/ga/ncdmeeting2011/ [accessed 30.9.2011]. 
[2] WHO. Global status report on noncommunicable diseases 2010. Geneva: WHO; 2011.

[3] Beaglehole R, Bonita R, Alleyne G, Horton R, Li L, Lincoln P, for The Lancet NCD Action Group. UN high-level meeting on non-communicable diseases: addressing four questions. Lancet 2011; 378:449-455.

[4] Block S, Webb P. Up in smoke: tobacco use, expenditure on food, and child malnutrition in developing countries. Economic Development and Cultural Change 2009; 58:1-23.

[5] World Economic Forum. Global risks 2011. Sixth ed. Geneva: World Economic Forum; January 2011; at: http://riskreport.weforum.org/ [accessed 30.9.2011]

[6] United Nations. Millennium Development Goals. Website at: http://www.un.org/millenniumgoals/ [accessed 30.9.2011].

[7] World Trade Organisation. Trade-related aspects of intellectual property (TRIPS) agreement (15 April 1004): http://www.wto.org/english/docs_e/legal_e/27-trips_01_e.htm [accessed 31.9.2011].

[8] Fink S, Rabinowitz R. The UN's battle with NCDs. Foreign Affairs, 20 September 2011: http://www.foreignaffairs.com/articles/68280/sheri-fink-and-rebecca-rabinowitz/the-uns-battle-withncds [accessed 30.9.2011].

[9] Magnusson R, Patterson D. Role of law in the global response to non-communicable diseases. Lancet 2011; 378:859-860.

[10] Symposium: Obesity: should there be a law against it. Australia New Zealand Health Policy. 2008: http://www.anzhealthpolicy.com/series/1743-8462-Aso [accessed 31.9.2011].

[11] Union for International Cancer Control (UICC). World cancer declaration. 2008; at: http://www.uicc.org/declaration [accessed 31.9.2011]

[12] Beaglehole R, Bonita R, Horton R. et. al., for the Lancet NCD Action Group and the NCD Alliance. Priority actions for the noncommunicable disease crisis. Lancet 2011; 377:1438-1447.

[13] WHO. WHO framework convention on tobacco control. WHA56.1 (entered into force 27 February 2005).

[14] WHO. Global strategy to reduce the harmful use of alcohol WHA63/13 - Annex 2 (Endorsed WHA May 2010).

[15] WHO. WHO global strategy on diet, physical activity and health. WHA57.17. (Endorsed WHA May 2004).

[16] WHO. Global status report on alcohol and health. Geneva: WHO; 2011.

[17] Tony Blair. Speech on healthy living. 26 July 2006, at:

http://webarchive.nationalarchives.gov.uk/+/http:/www.number10.gov.uk/Page9921 [accessed 31.9.2011]

[18] Thaler R, Sunstein C. Nudge: improving decisions about health, wealth, and happiness. New Haven: Yale University Press; 2008. 
[19] Freudenberg N, Galea S. The impact of corporate practices on health: implications for health policy. Journal of Public Health Policy 2008; 29:86-104, at 95.

[20] Atlantis E, Barnes E, Ball K. Weight status and perception barriers to healthy physical activity and diet behavior. International Journal of Obesity 2007; 32:343-352.

[21] Reeves M, Rafferty A. Healthy lifestyle characteristics among adults in the United States, 2000. Archives of Internal Medicine 2005; 165:854-857.

[22] WHO. World report on road traffic injury prevention. Geneva: WHO; 2004.

[23] Brownell K, Kersh R, Ludwig D, Post R, Puhl R, Schwartz M et. al. Personal responsibility and obesity: a constructive approach to a controversial issue. Health Affairs 2010; 29:379-387.

[24] Moodie R, Swinburn B, Richardson J, Somaini B. Childhood obesity - a sign of commercial success, but a market failure. International Journal of Pediatric Obesity 2006; 1(3):133-138.

[25] MacKenzie R, Imison M, Chapman S, Holding S. Mixed messages and a missed opportunity: Australian news media coverage of Clare Oliver's campaign against solaria. Medical Journal of Australia 2008; 189:371-374.

[26] Eisenberg D, Quinn B. Estimating the effect of smoking cessation on weight gain: an instrumental variable approach. Health Research and Educational Trust 2006; 41(6): 2255-2266.

[27] Schulze M, Manson J, Ludwig D, Colditz G, Stampfer M, Willett W, Hu F. Sugar-sweetened beverages, weight gain, and incidence of Type 2 diabetes in young and middle-aged women. JAMA 2004; 292:927-934.

[28] Rosenheck R. Fast food consumption and increased caloric intake: a systematic review of a trajectory towards weight gain and obesity risk. Obesity Reviews 2008; 9:535-547.

[29] Produce for Better Health Foundation. 2010 gap analysis: the fruit and vegetable challenge: how federal spending falls short of addressing public health needs. November 2010; at: http://www.pbhfoundation.org/about/donor_updates/ed/111910/ [accessed 31.9.2011].

[30] Sealing K. Attack of the balloon people: how America's food culture and agricultural policies threaten the food security of the poor, farmers, and indigenous peoples of the world. Vanderbilt Journal of Transnational Law 2006; 40:1015-1037.

[31] Lloyd-Williams F, O'Flaherty M, Mwatsama M, Birt C, Ireland R, Capewell S. Estimating the cardiovascular mortality burden attributable to the European Common Agricultural Policy on dietary saturated fats. Bulletin of the World Health Organization 2008; 86:535-541.

[32] Schäfer Elinder L. Obesity, hunger, and agriculture: the damaging role of subsidies. British Medical Journal 2005; 331:1333-1336.

[33] Nader R. Unsafe at any speed: the designed-in dangers of the American automobile. New York: Grossman, 1972.

[34] Malone R. The tobacco industry. In Wiist W, editor. The bottom line or public health: tactics corporations use to influence health and health policy, and what we can do to counter them. New York: Oxford University Press; 2010. Pp 155-191. 
[35] United States v Philip Morris Inc., Civil Action No. 99-2496 (GK), U.S. District Court for the District of Columbia, Amended Final Opinion of Judge Gladys Kessler, 8 September 2006, at $\$ 1510$, $\S \S 1597-1602$, and generally $\S 1403-1492, \S \S 1508-1704$, at: http://www.usdoj.gov/civil/cases/tobacco2/index.htm [accessed 31.9.2011].

[36] WHO. Guidelines for implementation of Article 5.3 of the WHO Framework Convention on Tobacco Control - on the protection of public health policies with respect to tobacco control from commercial and other vested interests of the tobacco industry. Decision FCTC/COP3(7). November 2008 .

[37] Brien S, Ronksley P, Turner B, Mukamal K, Ghali W. Effect of alcohol consumption on biological markers associated with risk of coronary heart disease: systematic review and metaanalysis of interventional studies. British Medical Journal 2011; 342:d636.

[38] Schütze M, Boeing H, Pischon T, Rehm J, Kehoe T, Gmel G. et. al. Alcohol attributable burden of incidence of cancer in eight European countries based on results from prospective cohort study. British Medical Journal 2011; 342:d1584.

[39] Baan R, Straif K, Grosse Y, Secretan B, El Ghissassi F, Bouvard V et. al. Carcinogenecity of alcoholic beverages. Lancet Oncology 2007; 8:292-293.

[40] Jernigan D. The global alcohol industry: an overview. Addiction 2009; 104 (Suppl. 1):6-12.

[41] Bond L, Daube M, Chrikritzhs, T. Access to confidential alcohol industry documents: from 'big tobacco' to 'big booze'. Australasian Medical Journal 2009; 1(3):1-25.

[42] Bond L, Daube M, Chikritzhs T. Selling addictions: similarities in approaches between big tobacco and big booze. Australasian Medical Journal 2010; 3(6):325-332.

[43] Swinburn B, Sacks G, Hall K, McPherson K, Finegood D, Moodie M et. al. The global obesity pandemic: shaped by global drivers and local environments. Lancet 2011; 378:804-814.

[44] Eric A. Finkelstein, Christopher J. Ruhm, Katherine M. Kosa, "Economic Causes and Consequences of Obesity" (2005) 26 Annual Review of Public Health 239-257.

[44] Arne Astrup, “Super-Sized and Diabetic by Frequent Fast-Food Consumption?” (2005) 365 Lancet 4-5.

[45] Barry M. Popkin, Michelle Mendez, "The Rapid Shifts in Stages of the Nutrition Transition: The Global Obesity Epidemic", in Ichiro Kawachi, Sarah Wamala (eds), Globalization and Health, Oxford: Oxford University Press, 2007, pp 68-80.

[46] Barry M. Popkin, Global Nutrition Dynamics: the World is Shifting Rapidly Towards a Diet Linked with Noncommunicable Diseases" (2006) 84 American Journal of Clinical Nutrition 289-298.

[47] Yach D, Khan M, Bradley D, Hargrove R, Kehoe S, Mensah G. The role and challenges of the food industry in addressing chronic disease. Globalization and Health 2010; 6:10.

[48] Yach D. Nutritional change is not a simple answer to non-communicable diseases. British Medical Journal 2011; 343:d5097. 
[49] Gilmore A, Savell E, Collin J. Public health, corporations and the New Responsibility Deal: promoting partnerships with vectors of disease? Journal of Public Health 2011; 33:2-4.

[50] Hashem K, Haigh C, Powell C. The irresponsibility deal? Why the government's Responsibility Deal is better for the food industry than public health. Children's Food Campaign; September 2011; at: www.childrensfood.org.uk [accessed 31.9.2011].

[51] Magnusson R Obesity prevention and personal responsibility: the case of front-of-pack food labelling in Australia. BMC Public Health 2010; 10:662, at: http://www.biomedcentral.com/14712458/10/662 [accessed 31.9.2011].

[52] Corporate Europe Observatory. A red light for consumer information: the food industry's $€ 1$ billion campaign to block health warnings on food; at: http://www.corporateeurope.org/ [accessed 31.9.2011].

[53] Gostin L. Public health law: power, duty, restraint. Berkeley: University of California Press; 2008, pp 28-38.

[54] World Bank. Human Development Network. The growing danger of non-communicable diseases: acting now to reverse course. Washington DC: World Bank; September 2011.

[55] World Bank. Human Development Network. Towards a healthy and harmonious life in China: stemming the rising tide of non-communicable diseases. Washington DC: The World Bank; 2011.

[56] Gostin L, Friedman E, Ooms G, et al. The Joint Action and Learning Initiative: Towards a global agreement on national and global responsibilities for health, 8(5) PLoS Medicine e1001031; doi:10.1371/journal.pmed.1001031 (May 10, 2011), available at http://www.plosmedicine.org/article/info\%3Adoi\%2F10.1371\%2Fjournal.pmed.1001031 [accessed 31.9.2011]. 


\section{Table 1}

Population-wide interventions for preventing cancer and NCDs that are likely to require legal and regulatory actions by governments for effective implementation ${ }^{13-16}$

\begin{tabular}{|c|c|c|}
\hline $\begin{array}{l}\text { Governance } \\
\text { reform }\end{array}$ & $\begin{array}{l}\text { - Institutional and governance reform to enable development } \\
\text { of a comprehensive and multi-sectoral approach to policy } \\
\text { development for diet, nutrition and physical activity, with } \\
\text { input from key sectors (agriculture, transport, education, } \\
\text { environmental and urban planning, sport, youth, industry, } \\
\text { finance, and media and communications). City and local } \\
\text { governments should have a legal mandate to play a leading } \\
\text { role (WHO Global Strategy on Diet, paras 38-44) }\end{array}$ & \\
\hline $\begin{array}{l}\text { Economic } \\
\text { strategies }\end{array}$ & $\begin{array}{l}\text { - Imposing higher excise taxes on tobacco to reduce demand } \\
\text { (FCTC Article 6) } \\
\text { - Increasing excise taxes on alcoholic beverages (WHO Global } \\
\text { Strategy on Alcohol, paras. 32-34) } \\
\text { - Penalties for smuggled and counterfeit tobacco and for } \\
\text { smuggled and informal alcohol, with appropriate investments } \\
\text { in monitoring and enforcement (FCTC Article 15; WHO } \\
\text { Global Strategy on Alcohol paras. 37-39) } \\
\text { - } \quad \text { Affordable treatment for tobacco dependence: supporting } \\
\text { interventions for smoking cessation in primary care; } \\
\text { affordable pharmacological therapies (FCTC Article 14) } \\
\text { Consider production incentives or reduced taxation on } \\
\text { healthier foods; higher taxation for foods to be consumed in } \\
\text { lower quantities (WHO Global Status Report, p 53) }\end{array}$ & $\begin{array}{l}\text { BEST BUY } \\
\text { BEST BUY }\end{array}$ \\
\hline $\begin{array}{l}\text { Environmental } \\
\text { controls }\end{array}$ & $\begin{array}{l}\text { - Protection from environmental tobacco smoke: smoking bans } \\
\text { in public places, including workplaces, public transport, bars } \\
\text { and restaurants (FCTC Article 8) }\end{array}$ & BEST BUY \\
\hline $\begin{array}{l}\text { Restricting } \\
\text { advertising }\end{array}$ & $\begin{array}{l}\text { - Implementing and enforcing bans on tobacco advertising, } \\
\text { promotion and sponsorship (FCTC Article 13) } \\
\text { - Implementing and enforcing restrictions on alcohol } \\
\text { advertising and promotion through the media, in community } \\
\text { settings and retail settings; restrictions on alcohol } \\
\text { sponsorship of sporting and cultural events (WHO Global } \\
\text { Strategy on Alcohol, paras. 29-31) } \\
\text { - Labelling controls, including health warnings on tobacco and } \\
\text { alcohol products (FCTC Article 11; WHO Global Strategy on } \\
\text { Alcohol para 36) } \\
\text { Constraints on advertising and promotion of foods and } \\
\text { beverages high in salt, sugar and saturated fat to children } \\
\text { (WHO Global Status Report, p 53; WHO. Set of } \\
\text { recommendations on marketing of foods and non-alcoholic } \\
\text { beverages to children WHA 64.14, adopted May 2010). }\end{array}$ & BEST BUY \\
\hline Regulating & - Prohibiting sales of tobacco and alcohol to and by children, & \\
\hline
\end{tabular}




\begin{tabular}{|c|c|c|}
\hline retail sales & $\begin{array}{l}\text { with proof of age requirements, and appropriate investments } \\
\text { in monitoring and enforcement (FCTC Article 16; WHO Global } \\
\text { Strategy on Alcohol, paras. 27-28) } \\
\text { - Restricting the availability of alcoholic beverages, including: } \\
\text { minimum purchasing age; restrictions on location and density } \\
\text { of retail outlets, and on hours of permitted sale through } \\
\text { licensing conditions (WHO Global Strategy on Alcohol, paras. } \\
\text { 27-28) } \\
\text { Health warnings at point of sale (see FCTC Article 12; see } \\
\text { WHO Global Strategy on Alcohol paras. 19,36) }\end{array}$ & \\
\hline $\begin{array}{l}\text { Product } \\
\text { reformulation }\end{array}$ & $\begin{array}{l}\text { - Encouraging food reformulation through public reporting of } \\
\text { food manufacturers' commitments to progressive reductions } \\
\text { in salt levels in food (WHO Global Strategy on Diet, para 41) } \\
\text { - Requiring food manufacturers to replace trans fats with } \\
\text { polyunsaturated fats (WHO Global Strategy on Diet, para 41; } \\
\text { WHO Global Status Report, p 52) } \\
\text { - Targets for replacing saturated with unsaturated fats in } \\
\text { products (WHO Global Status Report, p 53) }\end{array}$ & BEST BUY \\
\hline $\begin{array}{l}\text { Direct } \\
\text { constraints on } \\
\text { the behaviour } \\
\text { of individuals }\end{array}$ & $\begin{array}{l}\text { Drink-driving counter-measures, including random breath } \\
\text { testing, a maximum } 0.5 \mathrm{~g} / \mathrm{l} \text { blood alcohol concentration (BAC) } \\
\text { limits for adult drivers, with a reduced or zero limit for young } \\
\text { drivers (WHO Global Strategy on Alcohol, paras. 24-26; NCDs } \\
\text { Global Status Report p 51) } \\
\text { - Smoking restrictions (above) }\end{array}$ & BEST BUY \\
\hline Other strategies & $\begin{array}{l}\text { - } \quad \text { HBV vaccination } \\
\text { - Policies to improve health literacy and a healthy diet at } \\
\text { school (WHO Global Strategy on Diet, para 43) }\end{array}$ & BEST BUY \\
\hline $\begin{array}{l}\text { Supporting } \\
\text { breastfeeding }\end{array}$ & $\begin{array}{l}\text { - Legislation to protect women's right to breast-feed, without } \\
\text { harassment or discrimination }\end{array}$ & \\
\hline
\end{tabular}




\section{Table 2}

Ways in which legal and regulatory interventions can reduce the prevalence of behavioural risk factors for cancer and other NCDs

- Improving health infrastructure and governance: This includes creating agencies with a clear mandate to follow the evidence, to enforce legal requirements and to promote healthy lifestyles. It also includes cross-sectoral initiatives to encourage healthy policymaking in settings and government sectors beyond health; for example, transport, agriculture, sport and recreation, taxation and finance, local government, the workplace, or schools.

- Improving the informational environment: For example, by mandating the provision of information to consumers to encourage healthier decisions (eg food labelling, warnings on alcohol and tobacco products), and by banning or restricting the advertising of tobacco, alcohol and energy-dense, nutrient poor foods, especially to children.

- Economic strategies: Governments can encourage healthier behaviours by altering the costs of behaviour; for example, by raising taxes on tobacco products and alcoholic beverages. As an alternative to taxing, governments can spend; for example, through food programs to improve nutrition for vulnerable and low-income groups.

Governments can also create incentives for private-sector initiatives; for example, by giving tax relief for employers who invest in health promotion and risk factor prevention in the workplace.

- Improving the physical and built environment: Governments can use law to create healthier physical environments, through measures such as smoke-free laws, restrictions on the retail licensing of alcohol and tobacco, and by integrating health impact assessment within planning and development approval processes. National and/or regional governments can create a mandate for local governments to develop strategies to reduce risk factors for NCDs within the local environment, with targets and incentives for meeting performance.

- Regulating the manufacturing and retail sectors: While voluntary and self-regulatory standards may be appropriate in some areas, governments can impose technical legal requirements as well as performance standards upon businesses, employers, and providers of goods and services. These cover a wide range, from bans on trans fats in restaurant foods, to technical regulations about how obesity, smoking status and other risk factors can affect premiums and health insurance coverage.

- Social policies: Governments can use law as part of wider strategies to reduce socioeconomic disparities in health and to ensure equality of opportunity in accessing the conditions that are necessary to live a healthy life. Examples include direct financial assistance to vulnerable families, financing and incentives to attract supermarkets and fresh food outlets to underserved areas, as well as New York's microloans and licensing scheme to establish "green carts" selling fresh produce on city streets. 